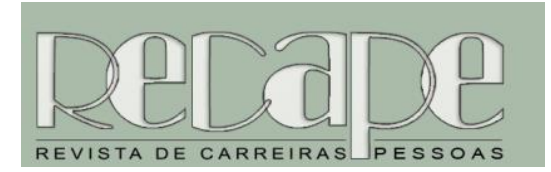

ISSN: 2237-1427

Vol. 7 | No. 3 | Ano 2017 Páginas 27-42

\section{Larissa Pagnussatto}

Psicóloga, Pós-Graduada em Psicologia Organizacional: Gestão

e Desenvolvimento de Pessoas

UNOESC

tathianaformenton@hotmail.com

\section{Michele Gaboardi Lucas}

Professora do Curso de Psicologia UNOESC

professor-silvio@hotmail.com

Dados para contato

Consultório de Psicologia Mlchele Gaboardi Lucas.

Rua Nereu Ramos 75 d Ed CPC Sala 1307-B

Centro

89801023 - Chapecó, SC - Brasil - Caixapostal: 363

Recebido em: 03/04/2017

Aprovado em: 16/10/2017

DOI:

http://dx.doi.org/10.20503/recape.v7i3.33517

\section{ÂNCORAS DE CARREIRA DE MULHERES DA GERAÇÃO Y}

\author{
Generation Y Women's Career Anchors
}

\section{RESUMO}

Através do inventario de âncoras de carreira de Schein, 1996, buscou-se identificar valores e aptidões pessoais que determinaram a escolha profissional das mulheres da Geração Y nascidas a partir de 1978 até o presente - e acadêmicas do curso de psicologia. $O$ inventário de âncoras de carreira mapeou as maiores frequências de resposta nas âncoras: Estilo de Vida (26\%) identificando que a Geração Y desenvolve sua carreira integrando as necessidades do indivíduo e da família; e âncora Vontade de servir e dedicação a uma causa (22\%) ao qual descreve valores e aptidões encontrados na profissão de psicólogo.

Palavras-chave: Desenvolvimento profissional. Âncoras de carreira. Geração Y.

\begin{abstract}
Throughout the inventory about career anchors (SCHEN 1996), who looked to identify personal values and aptitudes that determine the professional choices of women in generation $\mathrm{Y}$, those born from 1978 until this day, either academics of the psychology course. The career anchors inventory mapped the highest response frequencies in the anchors: Lifestyle (26\%) identifying that Generation $Y$ develops a career geared to their lifestyle, integrating the needs of the individual and the family. The anchor willingness to serve and dedicate to a cause (22\%) to which describes values and aptitudes found in the profession of psychologist is also an important aspect to considerate.
\end{abstract}

Keywords: Professional development. Career Anchors. Generation Y. 


\section{INTRODUÇÃO}

As mudanças sociais e econômicas da sociedade fizeram com que o termo carreira sofresse grandes mudanças no decorrer dos anos. Antigamente as pessoas serviam as organizações por toda a vida, e encaravam esse processo como um desenvolvimento desejado (BARUCH, 2011). Atualmente o termo carreira está associado à administração da vida pessoal e profissional, ou seja, o indivíduo se torna responsável pela gestão de sua carreira (LEMOS, 2010).

Para isso uma das estratégias de autoconhecimento utilizadas durante desenvolvimento profissional pode ser a âncora de carreira de Edgar Schein (1996). Que consiste em um inventário que busca identificar a inclinação profissional do indivíduo, que pode gerar autoconhecimento e clareza diante do gerenciamento de sua carreira (SCHEIN, 1996).

Além do desenvolvimento de carreira, outra questão significativa é o termo gerações. Dentre elas a abordada nesse estudo, é a geração $Y$ que se encontra nos princípios da construção de suas carreiras, são representados pela tecnologia e caracterizados por priorizar o lado pessoal quando se referem a quesitos profissionais (VELOSO; DUTRA; NATAKA, 2008).

Muitos estudos caracterizam a geração $\mathrm{Y}$, mas pouco se pesquisa sobre como eles estão gerenciando suas carreiras, e principalmente como as mulheres desta geração estão se organizando. Portanto, este trabalho buscou analisar as âncoras de carreira presente nas mulheres de geração $Y$, nascidas a partir de 1978, identificando se a âncora predominante tem relação com as características da geração $Y$, mapeando a âncora destaque nas acadêmicas de psicologia.

\section{Carreira e projeto profissional}

Os conceitos de carreira passaram por grandes mudanças nas últimas décadas, as empresas e organizações precisaram acompanhar o crescimento da economia, tecnologia e da sociedade em geral, assim a trajetória profissional se tornou mais complexa, dando origem a diferentes significados para o termo (BARUCH, 2011).

O conhecimento de carreira é histórico, começa-se a ser falado sobre o termo no século XIX, a ideia de carreira nasce com a sociedade industrial capitalista liberal. Mas é nos anos 80 que as empresas percebem que devem se preocupar em conduzir a carreira de seus colaboradores. O termo gestão e as discussões gerenciais consolidam a ideia de carreira (CHANLAT, 1995). 
Tradicionalmente a carreira era entendida como a adaptação de uma pessoa a uma ocupação escolhida. Sendo assim, carreira envolveria as ocupações e profissões, abarcando uma sequência de trabalhos correlacionados. Fica evidente nessa dinâmica a noção de hierarquia ou sequência de papeis dentro da empresa (BASTOS, 1997). Antigamente as pessoas pensavam em servir suas organizações por toda a vida, e isso era um exemplo de desenvolvimento almejado, por mais que não ocorresse, já nos dias de hoje, as pessoas anseiam ser servida pelas organizações e logo a duração da relação é diminuída há poucos anos. Diante de tantos avanços, a gestão de carreiras passou a ser pesquisada e refletida como uma condução individual, ou seja, as pessoas podem estar na gerência de sua trajetória profissional e fazer múltiplas escolhas (KILIMNIK, 2011). Sendo assim, "Carreira significa administrar aprópria vida pessoal e profissional cuidando do auto aperfeiçoamento e dos relacionamentos profissionais" (MOTTA, 2010, p. 12).

O termo carreira profissional é percebido como um processo social, complexo, que representa uma trajetória sócio profissional, "que relaciona a educação a inserção profissional, as dinâmicas da relação contratual, as aspirações sócios profissionais, etc. " (LIMA; CRUZ; RAFAEL, 2014, p. 4).

Para Schein (1996) o termo seguir carreira pode ser agregado como uma profissão, cuja vida profissional é bem estruturada e provoca evolução constante, mas na importância de inclinações profissionais o termo quer proferir "a maneira como a vida profissional de uma pessoa desenvolve-se ao longo do tempo e como é vista por ela" (SCHEIN, 1996 p. 19). Construir carreira exige dos indivíduos uma análise constante sobre si e sobre todos os aspectos que o envolve, este processo somente se inicia quando as escolhas feitas pelo individuo expressam seus conceitos pessoais (DUARTE, et. al, 2010).

Por meio do desenvolvimento de suas habilidades e competências, procura-se incentivar as pessoas a construírem sua carreira visando o progresso profissional. Recomenda-se seguir seus ideais, habilidades e vontades, porque as carreiras se constroem por meio da sequência de percepções individuais, comportamentos e atitudes, que autodesenvolvem suas experiências. Conservar a individualidade é um fator pretendido pelas gerações atuais, estar satisfeito com sua carreira pode significar não apenas possibilidades de contribuição e reconhecimentos, mas também de autopromoção. Sendo assim carreira significa "administrar a própria vida pessoal e profissional cuidando do auto aperfeiçoamento e dos relacionamentos profissionais" (MOTTA, 2010 p. 12).

Os autores Lima, Cruz e Rafael (2014) apontam que a carreira deve garantir uma integração de interesses individuais, como forma de atingir um sucesso profissional, as implicações sobre esse entendimento de carreira é a existência de um desejo, não só na 
evolução profissional, mas também de métodos de desenvolvimento que contemplem satisfação e realização em geral.

Para poder desenvolver uma carreira de sucesso é necessário que seja pensado e/ou organizado um projeto profissional. As autoras Dias e Soares (2009) apontam que ter um projeto profissional é seguir um caminho, tomar posição e ter o comprometimento de fazer escolhas quanto ao seu futuro. Para isso a investigação das âncoras de carreira, pode ser uma estratégia interessante na medida em que contribui para o autoconhecimento, permitindo delimitar as necessidades e valores norteando o planejamento de carreira.

\section{REFERENCIAL TEÓRICO}

\section{Âncoras de carreira}

As Âncoras de carreira originaram-se a partir de um estudo feito por Edgar Schein, em 1961, envolvendo 44 ex-alunos do programa de Mestrado na Escola Sloan de Administração (SCHEIN, 1996). As âncoras de carreira podem servir para, produzir critérios para formas de trabalho, identificar posições de sucesso e estabelecer experiência profissional. Para tanto, elas representam o interior do colaborador, seus interesses e capacidades, além de estimas e anseios (KILIMNIK, et. al, 2008).

Contudo Schein (1996) concluiu que conformea carreira das pessoas vão prosperando, elas começam a formar um autoconceito sobre si mesma, constituída a partir de experiências que proporcionaram um autoconhecimento. As âncoras de carreiras também podem ser definidas como aptidões, valores e objetivos que a pessoa não abre mão, mesmo quando surge a necessidade de escolher. Para compreender claramente este conceito se apresentam as oito âncoras de carreira descritas por Edgar Schein.

a) Aptidão Técnico-funcional: A pessoa é motivada quando consegue exercer suas aptidões, e fica satisfeita em saber que é perita. Dedica-se a especializações. Fiel à organização. O trabalho deve ser um desafio.

b) Aptidão Administrativa-geral: Tem a ambição de ser responsável pela administração, tomando as principais decisões. Considera a especialização como uma armadilha. Almejam subir os degraus hierárquicos da empresa. Responsabilidade em alto grau. Tem capacidade de identificar, analisar, sintetizar e solucionar problemas sobre condições de incerteza. 
c) Autonomia/Independência: A pessoa não suporta estar presa a horários e regras, e tem uma necessidade de fazer as coisas do seu jeito. Prefere trabalhos claramente delineados e com prazos.

d) Segurança/estabilidade: Necessidade de se sentir seguro e os eventos futuros devem parecer previsíveis. Procuram empresas sólidas e confiáveis, com programas de benefícios. Tendem a deixar sua carreira na mão dos empregadores.

e) Criatividade empreendedora: Necessidade de criar novos negócios próprios, com novos produtos, ou assumir uma nova empresa configurando-as de acordo com suas especificações. Gerar dinheiro é uma medida de sucesso. Provar que tem capacidade de criar negócios. Pessoa inquieta que busca sempre um novo desafio.

f) Vontade de servir, dedicação a uma causa: Necessidade de criar novos negócios próprios, com novos produtos, ou assumir uma nova empresa configurando-as de acordo com suas especificações. Gerar dinheiro é uma medida de sucesso. Provar que tem capacidade de criar negócios. Pessoa inquieta que busca sempre um novo desafio.

g) Puro desafio: A pessoa acredita poder conquistar qualquer coisa e qualquer pessoa, os sucessos esta em vencer obstáculos impossíveis e/ou pessoas muito forte. Busca emprego em que possa provar ao mundo suas superioridades.

h) Estilo de Vida: Geralmente a carreira não é importante, e se organiza de acordo com seu estilo de vida. Integrar as suas necessidades, da família e da carreira (flexibilidade). Não aceita ser transferida para outro espaço geográfico

Todas as pessoas podem ser descritas dentro de uma das oito âncoras de carreira. Neste exercício de autoanalise a pessoa deve buscar definir sua inclinação profissional, dandose conta de suas qualidades. De uma forma geral as pessoas estão preocupadas com estas questões, e a âncora de carreira ao qual se inclina é um fator de grande importância pessoal que acaba definindo uma autoimagem, ao qual vai prevalecer em todas as fases do desenvolvimento de sua carreira (SCHEIN, 1996).

Tomar conhecimento sobre a âncora de carreira principal permite o profissional a desenvolver estratégias de carreira que considere seus valores, habilidades e chances do mercado, ou seja, o autoconhecimento é o primeiro passo para a construção do projeto profissional e fundamental quando se torna indispensável à tomada de decisão sobre carreira (DUTRA, 2002).

As âncoras consolidam, conduzem e unificam a carreira de uma pessoa, ou seja, na vida profissional as âncoras são usadas para organizar experiências, criar critérios para tipos de trabalho de preferencias, identificar áreas que a pessoa pode contribuir com eficácia, 
identificar as ambições e o sucesso que a pessoa pode determinar para si (KILIMNIK, et. al, 2008).

São nos primeiros anos de carreira que os indivíduos aprendem sobre si, e é com o acumulo de experiências que ele também aprende a tomar decisões e situar o que é importante para sua vida, desta forma se institui o conceito de si mesmo que irá guia-lo e sua âncora deliberará suas escolhas (DIAS; SOARES, 2009). Sendo assim, é necessário conhecer as características da geração atual, para compreender quais suas perspectivas e objetivos relacionados à carreira.

\section{Geração Y}

Será utilizado como referência para delimitar a geração $Y$, pessoas nascidas a partir de 1978 até o presente. Apesar de haver algumas discordâncias quanto à definição cronológica da geração $\mathrm{Y}$, todos os autores concordam que a característica fundamental da geração, é o uso intenso da tecnologia, bem como o grande envolvimento com os avanços tecnológicos, decorrente da prosperidade econômica (CARVALHO NETO, et. al, 2012).

Os indivíduos da geração $Y$ nasceram no momento que o Brasil passava por problemas econômicos e reinstalava a democracia. Desenvolveram-se rodeados pela tecnologia, contudo são mais egocêntricos, protegem intensamente suas opiniões, dando valor às questões pessoais em relação a assuntos profissionais (VELOSO; DUTRA; NATAKA, 2008). Apesar da agilidade que as coisas acontecem, a geração $Y$ "busca o equilíbrio entre a vida pessoal e profissional" (CLARO, et. al, 2010, p. 11).

Um estudo realizado por Claro, et. al, (2010), aponta que a Geração Y quando orientada por metas trabalha mais determinada, é preciso ilustrar o que deve ser realizado, quais os resultados aguardados, e de gratificação oferecer uma boa remuneração. Esta geração busca horários e locais de trabalho flexíveis, prezam pela liberdade de estabelecer as suas atividades diárias a seu caráter. Eles anseiam o bom relacionamento com seus superiores, clientes e fornecedores, valorizando as empresas que investem no desenvolvimento de suas competências. De forma positiva eles esperam sempre estar potencializando seus conhecimentos e habilidades.

Vasconcellos, et. al, (2016) identificaram em sua pesquisa sobre a geração $Y$ no mercado de trabalho, que esta geração pondera, gostar do que se está fazendo, como fator extraordinário no seu trabalho, ou seja, a carreira que estão adotando deve representar satisfação pessoal. A geração $Y$ destacou gostar do aspecto autonomia e liberdade, levando em consideração a componente família na tomada de decisão profissional. Os autores Claro, 
et. al, (2010) complementam a ideia afirmando que para os jovens da geração $\mathrm{Y}$, a vida pessoal é o item mais respeitável em sua atividade profissional.

$\mathrm{Na}$ última pesquisa divulgada pela Companhia de Talentos, em 2015 na sua 14a edição, os resultados de mais de 67 mil respostas do questionário "Empresa dos sonhos dos jovens", pesquisando indivíduos entre 17 e 28 anos, apresenta que 89\% dos jovens sabem o que querem para carreira e quais são os próximos passos que precisam dar, porem a tarefa mais difícil é a tomada de decisão. Cerca de $84 \%$ dos jovens esperam encontrar uma empresa com olhar inovador para processos e produtos e $92 \%$ deles esperam que a empresa tenha um plano de carreira. Resumidamente os jovens da Geração $Y$ buscam por Inovação, Sustentabilidade, Valorização e Responsabilidade Socioambiental (COMPANHIA DE TALENTOS, 2015).

Outro ponto que chama a atenção é a grande quantidade de mulheres no mercado de trabalho, o papel que elas vêm assumindo e o desenvolvimento de carreira que estão estabelecendo.

\section{Gênero}

Atualmente a divisão do trabalho não está mais vinculada às condições sexuais, mas sim culturais. Homens e mulheres se distinguem fisicamente, e principalmente pelo papel que cumprem na sociedade. "As diferenças, apesar de marcarem a separação entre os sexos, não estão relacionadas diretamente com a atividade ou com o trabalho desenvolvido"(GOMES, 2005 p. 230).

Já as autoras McDonald, Brown, Bradley, (2011) fizeram uma pesquisa sobre a interação do gênero com as carreiras tradicional x carreira proteana, e perceberam que existe diferença entre os gêneros quando referem o desenvolvimento de suas carreiras. As mulheres pensam suas carreiras com objetivos a curto prazo, dando seriedade nos principais projetos das organizações como método de desenvolvimento de carreira ideal. As autoras também constataram que ambos os sexos creem que o sucesso da carreira é de encargo do individuo e não da empresa, ou seja, cada um é responsável por buscar oportunidades e ampliar suas habilidades superando empecilhos.

Dentre as profissões existentes, a psicologia é uma das que apresenta maior número de mulheres, por isso é interessante compreender o exercício da profissão, e as opções de desenvolvimento de carreira na área. 


\section{Carreira do Profissional de Psicologia}

Os princípios fundamentais da profissão de psicólogo é visar a qualidade de vida dos indivíduos e da sociedade, atuando com responsabilidade social, analisando a realidade política, social, cultural e econômica, contribuindo para o desenvolvimento da ciência (Conselho Federal de Psicologia, 2014).

Os indivíduos que optam por ser psicólogo consolidam na formação acadêmica suas preferencias por áreas do conhecimento, desenvolvendo sua carreira de acordo com suas características pessoais, habilidades e capacidades. Para tanto acaba desenvolvendo um perfil profissional de pessoas calmas, pacientes e tranquilas com disponibilidade de ouvir, mediar conflitos e ajudar pessoas (MAZER; SILVA, 2010).

Diante da expansão do acesso ao ensino superior, no que diz respeito às mulheres houve uma grande concentração de matriculas em cursos culturalmente compreendidos como carreiras femininas (BARROSSO; MELLO, 1975). A psicologia ocupa o quarto lugar em carreira considerada feminina (FERRETTI, 1975). Portanto, a psicologia não constitui uma carreira de discriminação, os salários, o número de horas, dificuldades na inserção ao mercado de trabalho e etc., não são diferentes entre homens e mulheres (ROSEMBERG, 1984).

Segundo Santos (2004) a escolha pela psicologia é uma possível cultura ocupacional, um conjunto de valores que abrangem o exercício da profissão, e fazem com que as pessoas se identifiquem ou não por ela. Pesquisando os acadêmicos de psicologia Magalhães, (2001) identificou que os principais motivos que os indivíduos escolhem a psicologia como profissão, é o desejo de ajudar os outros, interesse pelo conhecimento psicológico e competência interpessoal. Sentem-se gratificados quando percebem ser o responsável pelo progresso ou cura das pessoas, dando pouca importância ao retorno financeiro.

Os autores Bettoi e Simão (2000) pesquisaram algumas reflexões sobre a formação do psicólogo e identificaram que os ingressantes do curso de psicologia idealizam uma postura profissional, diante da profissão escolhida, e por algum tempo se questiona se ele possui determinada postura. A identidade do profissional de psicologia está voltada as necessidades da população em geral, ou seja, o profissional precisa estar sempre em aperfeiçoamentos, em movimento para poder atender as demandas da sociedade (BOCK, 1999).

A finalidade do capitulo a seguir, é apresentar a metodologia utilizada para a condução da pesquisa. Será apresentado o delineamento da pesquisa, as definições 
operacionais, os sujeitos, o instrumento de coleta e análise de dados, contemplando o objetivo geral e específicos da pesquisa.

\section{METODOLOGIA}

A pesquisa segue um encadeamento metodológico de ordem quanti-qualitativo com cunho descritivo. Os sujeitos pesquisados são mulheres, nascidas a partir de 1978, até o presente, e acadêmicas do curso de Psicologia da Universidade do Oeste Catarinense. $O$ instrumento para coleta de dados é denominado como Inventário de Âncoras de Carreira proposto por Schein, (1996). Em texto adaptado por Dutra e Albuquerque (2002) o inventário possui escala de avaliação composta por quarenta questões, assim o indivíduo aponta cada pergunta analisandose ela se aplica a seus valores, necessidades e capacidades individuais. Cada questão corresponde há uma das oito âncoras, e cada âncora tem cinco questões representativas, a mais assinalada recebe maior pontuação e melhor descreve o indivíduo.

A análise dos dados foi classificada, codificada e tabulada com o auxilio do programa Microsoft Office Excel, gerando um gráfico com as frequências relativas das duas principais âncoras de cada sujeito, possibilitando uma boa perspectiva de analise descritiva quanto à correlação da âncora predominante nas mulheres com as características da geração Y.

Esta pesquisa após análise do comitê de ética da Universidade, para sua execução solicitou-se permissão a Coordenadora do curso, e após o seu aceite as acadêmicas pesquisadas, assinaram Termo de Consentimento Livre e Esclarecido - TCLE. Foi disponibilizado via e-mail o resultado da âncora de carreira que as pesquisadas obtiveram.

\section{DISCUSSÕES E RESULTADOS}

Quantificando os dados obtidos por meio do Inventário de Âncoras de Carreira, podese observar na Tabela 3 a frequência de resposta, tabulando as duas maiores média de cada Inventario, a cada uma das oito âncoras descritas por Schein (1996).

Tabela 3. Frequência de resposta ao Inventário de Âncoras de Carreira.

\begin{tabular}{|c|c|}
\hline Ancora de carreira & Frequência de resposta \\
\hline Aptidão Técnico-funcional & 15 \\
\hline Aptidão Administrativa - geral & 1 \\
\hline Autonomia/Independência & 16 \\
\hline Segurança/Estabilidade & 24 \\
\hline Criatividade empreendedora & 13 \\
\hline Vontade de servir e dedicação a uma causa & 30 \\
\hline
\end{tabular}




\begin{tabular}{|c|c|}
\hline Puro Desafio & 8 \\
\hline Estilo de Vida & 38 \\
\hline
\end{tabular}

Fonte: elabora pelas autoras

Considerando as oito âncoras de carreira, o maior percentual de respostas (26\%) está ligado ao Estilo de Vida, para tanto Schein (1996), descreve que as pessoas que se orientam pela inclinação profissional em Estilo de Vida geralmente não apresentam a carreira como algo extremamente importante, toda sua essência é voltada ao seu estilo de vida, sendo assim, a carreira que exerce deve estar "integrada as necessidades do indivíduo, da família e da carreira" (SCHEIN, 1996 p. 58-59). O que pode ser relacionado com a geração $Y$ ao qual quando mencionado o termo carreira, pondera estar gostando do que faz, almejando a satisfação pessoal, sendo toda a sua atividade profissional um equilíbrio entre a vida pessoal e profissional. (CLARO, et.al, 2010; VASCONCELLOS, et.al ,2016; VELOSO; DUTRA; NATAKA, 2008). Percebe-se que as formas de pensar e agir da geração $Y$ estão em coerência com os valores e aptidões descritos na âncora Estilo de Vida, uma carreira norteada pelo sentimento de satisfação e equilíbrio entre as esferas profissionais e pessoais.

Outras pesquisas sobre geração $\mathrm{Y}$ e âncoras de carreiras apresentaram resultado similares, como em Vasconcelos, et.al (2010) em média $22 \%$ dos pesquisados se enquadraram na âncora Estilo de Vida; em pesquisa com consultores juniores de empresas e sujeitos da geração Y, Medeiros, Medeiros, Junior (2014) quantificaram 37\% do total de respostas na âncora Estilo de Vida; o que confirma a afirmação de Schein (1996) que esta inclinação profissional representa uma tendência na sociedade.

Em pesquisa com homens e mulheres da geração $Y$, o autor Moreira (2014) constatou que as mulheres tem mais inclinação sobre a âncora Estilo de Vida, isso porque antigamente, as mulheres desenvolviam suas carreiras no modo de agir dos homens, atualmente elas assumem características voltadas para seus valores pessoais, isso corresponde que as mulheres vem pensando suas carreiras com objetivos a curto prazo, desenvolvendo uma carreira ideal de acordo os aspectos que analisa importante em sua vida (MCDONALD, BROWN, BRADLEY, 2011; ANDRADE, 2009; SILVA, 2011).

Em pesquisa com a Geração Y os autores Rudge et.al (2017) identificaram que o equilíbrio entre a vida pessoal e profissional dos jovens da Geração Y foi um fator decisivo levado em consideração na hora de sair de uma empresa, sendo a falta de tempo para assuntos pessoais o maior fator. A pesquisa também apresenta que suas motivações estão na realização profissional e na flexibilidade para executar o serviço.

A segunda âncora com maior frequência (21\%), Vontade de servir e dedicação a uma causa representam pessoas que buscam no trabalho uma forma de incorporar seus valores, expressando desejo de melhorar o mundo (SCHEIN, 1996). Este dado confirma os 
apontamentos dos autores ao qual a Geração $Y$ costuma se relacionar com grupos e apresenta grandes preocupações sociais e ambientais (VASCONCELLOS, et.al, 2016; CLARO, et.al, 2010).

Segundo Schein (1996) quem se enquadra nessa inclinação, almeja trabalhar com pessoas, servindo a humanidade, sendo o principal motivo pelo qual as pessoas escolhem a psicologia como profissão o desejo de ajudar o outro e atender as demandas da sociedade (MAGALHÃES, 2001; BOCK, 1999). Desta forma, pode-se relacionar que a âncora de carreira Vontade de servir e dedicação a uma causa é a que melhor descreve o exercício da profissão de psicólogo, ao qual possibilita o profissional se dedicar a causas nobres da sociedade proporcionando qualidade de vida.

As mulheres em suas trajetórias sociais citadas a da Geração Y, parecem também apresentar fortes inclinações para a âncora Vontade de servir a dedicação á uma causa, principalmente a crescente inclusão e participação de mulheres em eventos feministas, empreendedores, políticos, sociais, com objetivo de melhorar aspectos importantes da sociedade. Tal fato é recorrente da mulher contemporânea e das novas características de carreira que a Geração $Y$ vem assumindo, ou seja, são responsáveis por suas escolhas profissionais analisando suas aptidões e valores pessoais (ANDRADE, 2009).

As âncoras com menores evidências foram: Criatividade empreendedora, como pessoas que tem necessidades de criar novos negócios, produtos ou organizações, nem sempre a criatividade é artística, mas sim de cunho empreendedor; Puro desafio, pessoas que almejam o sucesso enfrentando empecilhos impossíveis e que mostrem sua capacidade de solucionar problemas difíceis, ou seja, toda a suas trajetórias profissionais são determinar por desafios constantes, e por último, e apenas uma frequência de resposta, a âncora aptidão administrativa-geral, que destaca profissionais que necessitam alcançar cargos de gerencia e grande responsabilidade dentro de uma organização, são motivados pela execução de liderança e motivação crescendo hierarquicamente dentro das organizações (SCHEIN, 1996). Entende-se que estas âncoras tiveram menos ancorados, porque suas características são antagônicas das da geração $\mathrm{Y}$, principalmente porque todas exigem um foco de vida na profissão e não nos aspectos pessoais, tanto planejando e investindo em novas organizações, quanto desenvolvendo estratégias para soluções de grandes desafios e principalmente por assumir cargos hierárquicos dentro das organizações, são os principais fatores destas âncoras que não preconizam os anseios da Geração Y.

É interessante ressaltar, que a âncora Aptidão administrativa-geral teve apenas uma frequência de resposta, confirmando o que a literatura apresenta sobre a mudança da forma de pensar carreira, onde as gerações Baby-boomers e $\mathrm{X}$ acreditavam que era imprescindível servir suas organizações, assumindo cargos hierárquicos, onde 0 mais alto nível 
organizacional representava melhor status social, e com o passar das gerações a forma de pensar carreira foi reestruturada tornando-se mais aberta e diversificada (KILIMNIK, 2011; BARUCH, 2011).

Diante de todas as mudanças geracionais nos quesitos de carreira e gênero, também destaca-se as pesquisas de Moreira (2014), Gomes, et.al (2013) e Vasconcelos, et.al, (2010), de que as mulheres da Geração $Y$ tem menos disposição em se enquadrar nas âncoras Administrativo Geral e Criatividade Empreendedora, e melhor se encaixando na âncora "Estilo de Vida".

Outras pesquisas recentes que analisam a relação das âncoras de carreira com as Gerações obtiveram os mesmos resultados, como Reis; Graziano; Osvaldo (2016) que identificaram a predominância da âncora Estilo de Vida em jovens da região de São Paulo, sendo a menor frequência de respostas na âncora Aptidão Administrativa-geral. Pode-se citar também, a pesquisa de Cabral e Kilimnik (2017) sobre a atração e retenção de jovens profissionais engenheiros, identificaram que os jovens recém formados são atraídos por empresas que forneçam crescimento e desenvolvimento profissional aliados a qualidade de vida e bom ambiente de trabalho, apresentando nesta pesquisa as principais âncoras predominantes em Puro Desafio e Estilo de Vida salientando que as âncoras também servem para reter e atrair talentos dentro das organizações (CABRAL; KILIMNIK 2017)

\section{CONSIDERAÇÕES FINAIS}

A pesquisa realizada com mulheres da Geração $Y$ e acadêmicas de psicologia obteve o resultado como ponto de referência no desenvolvimento de carreira à âncora Estilo de Vida, sendo que $26 \%$ dos sujeitos se enquadraram neste perfil. Considerando os resultados, Schein (1996) ressalta que os sujeitos norteados por esta âncora organizam toda a sua trajetória profissional em torno do seu estilo de vida, são amplamente motivados em suas carreiras, porém ela precisa integrar as necessidades pessoais, familiares e da carreira.

Desta forma, a pesquisa atendeu aos objetivos propostos, identificou-se que a inclinação profissional das acadêmicas em Estilo de Vida, está em concordância com os anseios da Geração $Y$, quando se fala em relação à carreira. Os sujeitos da geração $Y$ ancorados em Estilo de Vida encontram no projeto profissional uma solução para desenvolver sua carreira e fazer escolhas quanto ao seu futuro, estabelecendo metas a curto e longo prazo, podendo assim atender as necessidades pessoais e familiares.

Identificou-se a presença de alta frequência de resposta na âncora Vontade de Servir e Dedicação a uma causa, já que a mesma apresenta características e valores concomitantes com a profissão em psicologia. A inclinação descreve que o profissional que apresenta tal 
ancora, tem o desejo de melhorar o mundo e servir a humanidade e a profissão de psicologia proporciona qualidade de vida aos sujeitos e sociedade, escolhendo a profissão a partir de seus valores pessoais.

A sugestão para estudos futuros consiste em analisar as âncoras de carreira dos homens da geração $\mathrm{Y}$, e acadêmicos do curso de psicologia, identificando se existe diferenciação de frequência de resposta à âncora Estilo de Vida e Vontade de Servir e dedicação a uma causa, analisando as questões de gênero na gestão de carreira.

\section{REFERÊNCIAS}

ANDRADE, G. A. Carreira tradicional versus carreira proteana: um estudo comparativo sobre a satisfação com a profissão, carreira e emprego. Dissertação de Mestrado. Belo Horizonte, 2009.

BAROSSO, C.L.M; MELLO, M.N. O acesso da mulher ao ensino superior brasileiro. Cadernos de Pesquisa, 1975.

BARUCH, Y. Transformações nas carreiras: de trajetórias lineares para multidirecionais. In: KILIMNIK, Z (org). Transformações e Transições nas carreiras: estudos nacionais e internacionais sobre o tema. Rio de Janeiro: Qualitymark, 2011.

BASTOS, A. V. B. A escolha e o comprometimento com a carreira: Um estudo entre profissionais e estu-dantes de Administração.Revista de Administração, 1997.

BETTOI, W; SIMÃO, L. M. Profissionais para si ou para os outros? Algumas reflexões sobre a formação dos psicólogos. Psicologia ciência e profissão, 2000.

BOCK, A. M. B. A psicologia a caminho do novo século: identidade profissional e compromisso social. Estudos de Psicologia, 1999.

CABRAL, E.S.M; KILIMNIK, Z.M. Fatores condicionantes da atração e retenção de jovens profissionais e Âncoras de Carreira: estudo om engenheiros de empresa construtora de obras de infraestrutura de Minas Gerais.Revista Recape, 2017.

CARVALHO NETO, A et.al.Executivos jovens e seniores no topo da carreira: conflitos e complementaridades. Revista REAd, jan/abr 2012.

CHANLAT, J. F. Quais carreiras e para qual sociedade?RAE - Revista de Administração de Empresas, São Paulo, nov./dez. 1995.

CIA DE TALENTOS. Pesquisa:Empresa dos Sonhos dos Jovens 2015. Disponível em:<http://www.ciadetalentos.com.br/esj/>. Acesso em: 29/03/2016. 
CLARO, J. A et. al. Estilo de Vida do Jovem da "Geração Y" e suas Perspectivas de Carreira, Renda e Consumo. XIII SEMEAD - Seminários em Administração. Setembro de 2010.

CONSELHO FEDERAL DE PSICOLOGIA. Código de ética do profissional Psicólogo, novembro de 2014.

DIAS, M. S. L; SOARES, D. H. P. Planejamento de carreira: uma orientação para estudantes e universitários. São Paulo: Vetor, 2009.

DUARTE, M. E, et. al. A construção da vida: um novo paradigma para entender a carreira no Século XXI. Revista Interamericana de Psicologia, 2010.

DUTRA, J. A gestão de carreira. In:FLEURY, M. T. L (org). As pessoas na organização. São Paulo: Editora Gente, 2002.

FERRETTI, C.J. A mulher e a escolha vocacional. Fundação Carlos Chagas, dez de 1975.

GOMES, A. F. O outro no Trabalho: mulher e gestão. Revista de Gestão USP. São Paulo, julho/setembro, 2005.

GOMES, D. F. N, et. al. Âncoras de carreiras: revisão do conceito de mobilidade a partir de estudo com egressos do curso de administração em dois momentos - 2007 e 2010 . Revista Recape: carreiras e pessoas, março de 2013.

KILIMNIK, Z. M, et al. Seriam as âncoras de car-reiras estáveis ou mutantes?: Um estudo com profissionais de Administração em transição de carreira.Revista Brasileira de Orientação Profissional,2008.

KILIMNIK, Z. M. Transformações e Transições nas carreiras: estudos Nacionais e Internacionais sobre o tema. Rio de Janeiro: Qualitymark, 2011.

LEMOS, A. H.C. Empregabilidade e Individualização da Conquista do Emprego. In: BALASSIANO, M; COSTA, I. S. A (org). Gestão de carreiras: dilemas e perspectivas. - São Paulo: Atlas, 2010.

LIMA, R.; CRUZ, R. B.; RAFAEL, M. Estudo das preocupações de carreira em aconselhamento: uma nova abordagem para a promoção do bem-estar dos indivíduos. Revista Brasileira de Orientação Profissional, jul./dez. 2014.

MAGALHÃES, M. Eu quero ajudar as pessoas: a escolha vocacional da psicologia. Psicologia ciência e profissão, junho de 2001.

MAZER, S.M; SILVA, L.L.M. Identidade profissional do psicólogo: uma revisão da produção cientifica no Brasil.Psicologia ciência e profissão, 2010. 
MCDONALD, P; BROWN, K; BRADLEY, L. As trajetórias de Carreiras Tradicionais estão dando passagem asproteanas? In: KILIMNIK, Z (org). Transformações e Transições nas carreiras: estudos nacionais e internacionais sobre o tema. Rio de Janeiro: Qualitymark, 2011.

MEDEIROS, C.R.O; MEDEIROS, L; JÚNIOR, V.M.V. Âncoras de Carreira e Geração Y: um estudo com consultores de empresas juniores. Revista Recape, São Paulo, 2014.

MOREIRA, S. A. S. Homens e Mulheres da Geração $Y$ e suas Âncoras de Carreira.EnANPAD, Rio de Janeiro, setembro de 2014.

MOTTA, P. R. Reflexões sobre a customização das Carreiras Gerenciais: a Individualidade e a Competitividade Contemporânea. In: BALASSIANO, M; COSTA, I. S. A (org). Gestão de carreiras: dilemas e perspectivas. São Paulo: Atlas, 2010.

REIS, T.A; GRAZIANO, G.O; OSVALDO, Y.C. Como as âncoras de carreira de Edgar Schein influenciaram na escolha da carreira feita por alunos de universidade do interior de São Paulo. Revista Recape, 2016

ROSEMBERG, F. Afinal, porque somos tantas psicólogas?Psicologia ciência e profissão, 1984.

RUDGE, M et.al.Geração Y: um estudo sobre suas movimentações, valores e expectativas. Revista Recape, 2017.

SANTOS, F. Juventude. Consumo e Globalização: Uma Análise Comparativa.Instituto Superior de Ciências do Trabalho e da Empresa. Fev, 2004.

SCHEIN, E. Identidade profissional: como ajustar suas inclinações a suas opções de trabalho. Tradução Margarida D Black. São Paulo: Nobel, 1996.

SILVA. T.M. Carreira feminina: a importância das mulheres nas organizações. 31/05/2011. Disponível em: http://www.rh.com.br. Acessado em: 03/11/2016.

USP - Universidade de São Paulo. Âncoras de Carreira. Texto adaptado por Joel S. Dutra e Lindolfo G Albuquerque do livro de Edgar Schein - CareerAnchor - em formato de apostila para uso em aula. USP, 2002.

VASCONCELLOS, S. J. L et.al.A geração $Y$ no mercado de trabalho: um estudo comparativo entre gerações.Psicologia: ciência e profissão, jan/mar, 2016.

VASCONCELOS, K. C. A et.al. A geração $Y$ e suas âncoras de carreira.Revista Gestão.Org. mai/ago2010.

VELOSO, E; DUTRA, J; NAKATA, L. Percepções sobre carreiras inteligentes: diferenças entre gerações $Y, X$ e babyboomers. Rio de Janeiro, EnANPAD, setembro de 2008. 